\author{
Rafael Rodiguez Loucel \\ Vicerreclor de Investigaciones y \\ Proyectión Social de la UIEC
}

\section{SECTORES COMO El}

AGROPECUARIO,

COMERCIO $Y$

CONSTRUCCIÓN NO

PRESENTAN SIGNOS

ClaROS dE

RECUPERACIÓN, POR El

CONTRARIO los dos

ÚlTIMOS SECTORES

MENCIONAdOS

MANIFIESTAN

TENDENCIAS

dECliNANTES Y El

PANORAMA GENERAL dE

la producCión ES UNA

dEsACElERACIÓN

CONTINUA EN El RITMO

$\therefore d E$ la aCrividad

ECONÓMICA

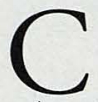

uando se efectúa un análisis económico es usual y tradicional recurrir a cifras para respaldar algunas aseveraciones o elementos de juicio, práctica que será sólo eventualmente respetada en este pequeño ensayo, por dos sencillas razones; la primera, por la carencia de indicadores trimestrales oportunos y la segunda, por la pérdida de credibilidad de algunas cifras estratégicas; sobre todo, aquellas que pretenden fijar una situación mensual o trimestral, con cifras improvisadas que favorecen una aparente buena gestión, con propósitos políticos que anulan la percepción genuina y técnica. Como alguien dijese, "las cifras no mienten, el que miente es el que las fabrica", o la alusión pertinente en un reconocido texto de la Doctora Joan Robinson, llamado "La Falacia de las Estadisticas".

En otro contexto, hay relieves del cuadro económico que son fáciles de percibir y que no requieren del testimonio estadístico, entre ellos la desaceleración económica, los límites del crecimiento, la pobreza, el posible incremento de la inflación, el aumento del desempleo, la pérdida de comperitividad productiva y de los términos de intercambio en un mundo de fronteras comerciales y financieras abiertas y de fácil acceso (internacionalización de los negocios). A sí mismo la poca flexibilidad presupuestaria, la reducción de la demanda crediticia que incrementa las posibilidades de riesgo crediticio y las necesidades de fusión y modernización del servicio financiero, la persistente política monetaria restrictiva y las altas posibilidades de continuidad de esa práctica forzada por la coyuntura fiscal.

El período que sucede a un evento eleccionario es supuestamente propicio para la aplicación de una estrategia que podría coadyuvar a una reactivación de corto plazo, como paso inicial a un crecimiento sostenible. El momento económico que se analiza es circunstancial, pero tomando en cuenta que la gran mayoría de los problemas que aquejan al país son de orden estructural, más que coyuntural, se parte de un momento. Las Medidas que se mencionan se consideran necesarias y convenientes no sólo para resolver el corto plazo, sino para la viabilidad económica a mediano y largo plazo. En este contexto no caben decisiones improvisadas que sólo servirían nuevamente para garantizar una sobrevivencia prorrogable.

El esquema o contenido es el tradicional, partiendo de la corriente real de la economía en la cual se examina la situación sectorial productiva, empleo y precios, continuando con la corriente financiera conformada por la sicuación fiscal y monetaria. La novedad quizás se ha logrado con el diferente enfoque de la circunstancia y la óprica objetiva del futuro reciente, sin compromiso alguno, y sin el riesgo de una falsa y poco fundamentada perspectiva estadística.

\section{Producción y Precios}

La tendencia de la producción medida a través del Producto Interno Bruto, es cada vez más decreciente. En 1999 y en términos reales éste alcanzó el 2.1\% de crecimiento, indicador que al ser revisado recientemente fue definido en $2.6 \%$, punto siete por ciento menos que en 1998 y bastante menor que el promedio del primer quinquenio de los noventa. Para el año 2000 se habla de una meta de $3.2 \%$, según el Programa Monetario del Banco Central de Reserva (BCR), basada en supuestos sobre volúmenes de producción, exportación y precios de café, así como exportación e importación de bienes, incluso inflación externa; todos difíciles que sean realidad, pero que por de pronto tendrán que aceptarse para asignarle cierta credibilidad al organismo productor de estadísticas económicas.

A pesar de declaraciones oficiales de una reactivación en los primeros meses del año, las impresiones recogidas por Fundación Salvadoreña para el Desarrollo Económico y Social (FUSADES) en su encuesta trimestral muestran una perspecriva diferente y sectores como el agropecuario, comercio y construcción no presentan signos claros de recuperación, por el contrario los dos últimos sectores mencionados manifiestan tendencias declinantes y el panorama general de la producción es una desaceleración continua en el ritmo de la actividad económica.

Las elecciones, así como otros factores distorsionantes aparentemente han influido en el comportamiento sectorial, pero no han sido los factores 
determinantes. Las expectativas no favorables influidas por la violencia, incrementada en los últimos meses por la carencia de una definición en la política económica del actual Gobierno, más la frecuente reducción de los pocos productos de exportación han tenido mayor injerencia en los resultados que los factores netamente políticos.

Sectores productivos que tradicionalmente han sido la base relativa y absoluta del crecimiento productivo global, como ya se mencionó, presentan señales de una tendencia de mediano plazo de estancamiento. La tendencia inflacionaria en los meses recientes ha sido hacia la baja, en parte por la política monetaria restricriva, $y$ en otra, por la presencia de una demanda interna efectiva reducida (consumo e inversión), lo cual también ha afectado el ritmo de crecimiento económico del país.

La inflación baja y hasta negativa en algunos meses se ha mantenido a pesar de que productos y servicios importantes en la composición de la canasta básica han experimentado incrementos en su precio de adquisición, debido a que han sido incluidos en la lista del Impuesto al Valor Agregado (IVA). En tal sentido, la probabilidad de un incremento en la inflación "debiese ser eminente".

Siempre con relación a la inflación, FUSADES ha expresado en un informe reciente: "La experiencia internacional parece indicar que los esfuerzos de las autoridades para una reducción importante de la inflación desde niveles que ya son bajos, de un sólo dígito, fácilmente significa costos en términos de un menor crecimiento económico, el caso salvadoreño parece confirmarlo". Esto último, desde el punto de vista de una política financiera que persigue como objetivo primordial, esencial y prioritario, la estabilidad de la moneda. Más allá de factores de demanda real y de política financiera, existen otras medidas de estímulo productivo sectorial y de necesidades presupuestarias que propician incrementos en los precios de los bienes $y$ servicios, no precisamente por un incremento en la demanda o una escasez de los mismos, si no por incrementos de precios "por decreto" y que podrían ser una especie de detonador de un aumento generalizado de precios de productos y servicios. Nos referimos al caso específico de los combustibles, de las frutas y verduras, que ocupan una ponderación importante en la estructura de la canasta básica.

\section{Sector Externo}

A nivel de relaciones externas, El Salvador continúa una tendencia preocupante de debilidad comercial por el ensanchamiento negativo de los bienes y servicios que se venden al exterior y lo que se compra del resto del

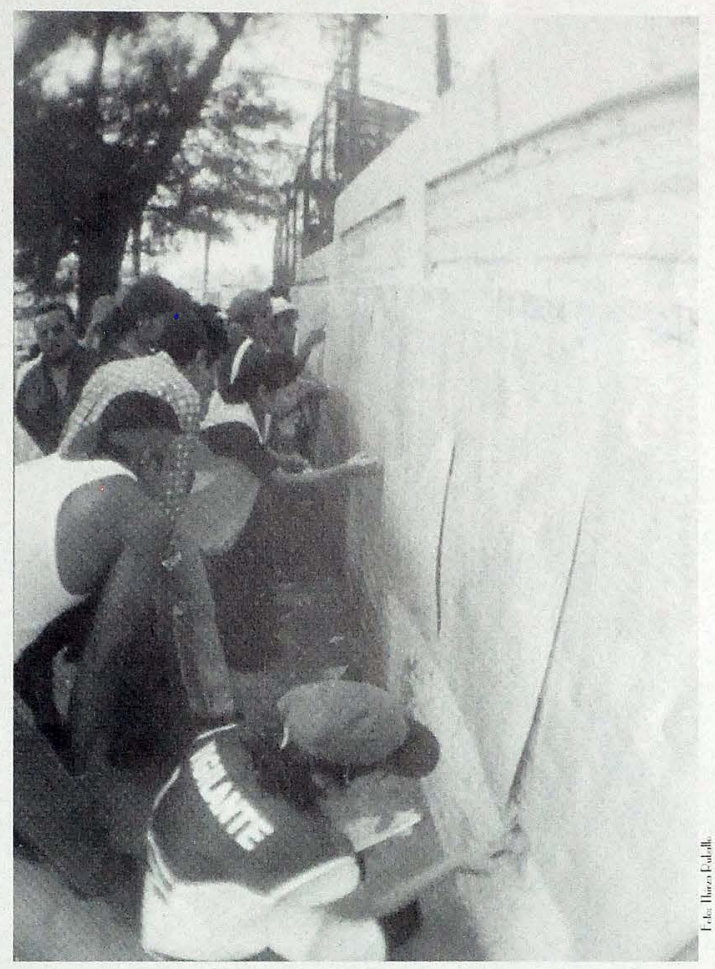

mundo. Circunstancia, que en forma deliberada o no, se ha minimizado dentro de una perspectiva de corto plazo, al enfatizar resultados positivos en términos de balanza en cuenta corriente, en los cuales el elemento estratégico ha sido las remesas familiares. La balanza comercial es cada vez más negativa, debido a la caída de las cotizaciones mundiales del café y del azúcar; la menor dinamia de la economía internacional; la mayor competitividad de los productos asiáticos y la pérdida relativa de dinamismo en la actividad maquilera, factores externos a los que se agrega la pérdida acumulada de competitividad de los productos salvadoreños potencialmente exportables.

En lo que concierne a la composición de las exportaciones, las maquilas han pasado a ser las más importantes en la estructura. Estas superan un poco más de cinco veces a las exportaciones de café, han mostrado un moderado dinamismo. Actividad en la cual se ha

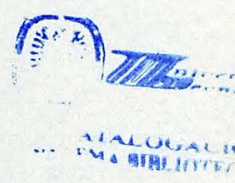

entorno 7 
registrado una desviación del comercio por la puesta en marcha de los tratados internaconales de comercio y por las depreciaciones de monedas de los países asiáticos, la menor productividad real de la mano de obra salvadoreña y el incremento de los costos de transferencia local. Las exportaciones de productos tradicionales con destino a Centroamérica se han visto afectadas por la menor capacidad de compra que ocasiona una menor dinamia económica en la región; por su parte, las exportaciones de bienes no tradicionales hacia mercados fuera de la región han aumentado en forma modesta y aún cuando dificilmente cuantificable. Se asegura que factores como la apreciación real de la moneda en comparación con los países de destino tradicional de bienes y los obstáculos no arancelarios por parte de naciones potencialmente receptoras de bienes salvadoreños, son los que mayormente inciden en ese comportamiento.

Por el lado de las importaciones, es significativa la reducción reciente de las importaciones de bienes intermedios y de capital, en contraste con el relativo aumento de las importaciones de consumo. Lo que es consecuente con la desaceleración económica en promedio y especificamente a la menor actividad del sector agropecuario, caracterizado por una demanda efectiva de insumos tradicionalmente alta.

Un auténtico problema está a la vista, si es que no se quiere ocultar y es la importancia que ha alcanzado la generación de divisas de la mano de obra laborando en el exterior en los factores de producción interna. En contraste, la propensión media a importar se mantiene en niveles altos semejantes a un pais altamente productivo y con capacidad corriente de importación de una nación con una base exportadora amplia y robusta; o simplemente un pais desarrollado, aún cuando la propensión marginal a adquirir productos extranjeros se ha visto disminuida por la desaceleración de la economía, lo cual ha contribuido a que la brecha comercial con el exterior no se haya ensanchado aún más.

El menor énfasis a las remesas familiares como estratégia para los resultados en cuenta corriente poce negativos y su importancia en la acumulación de reservas

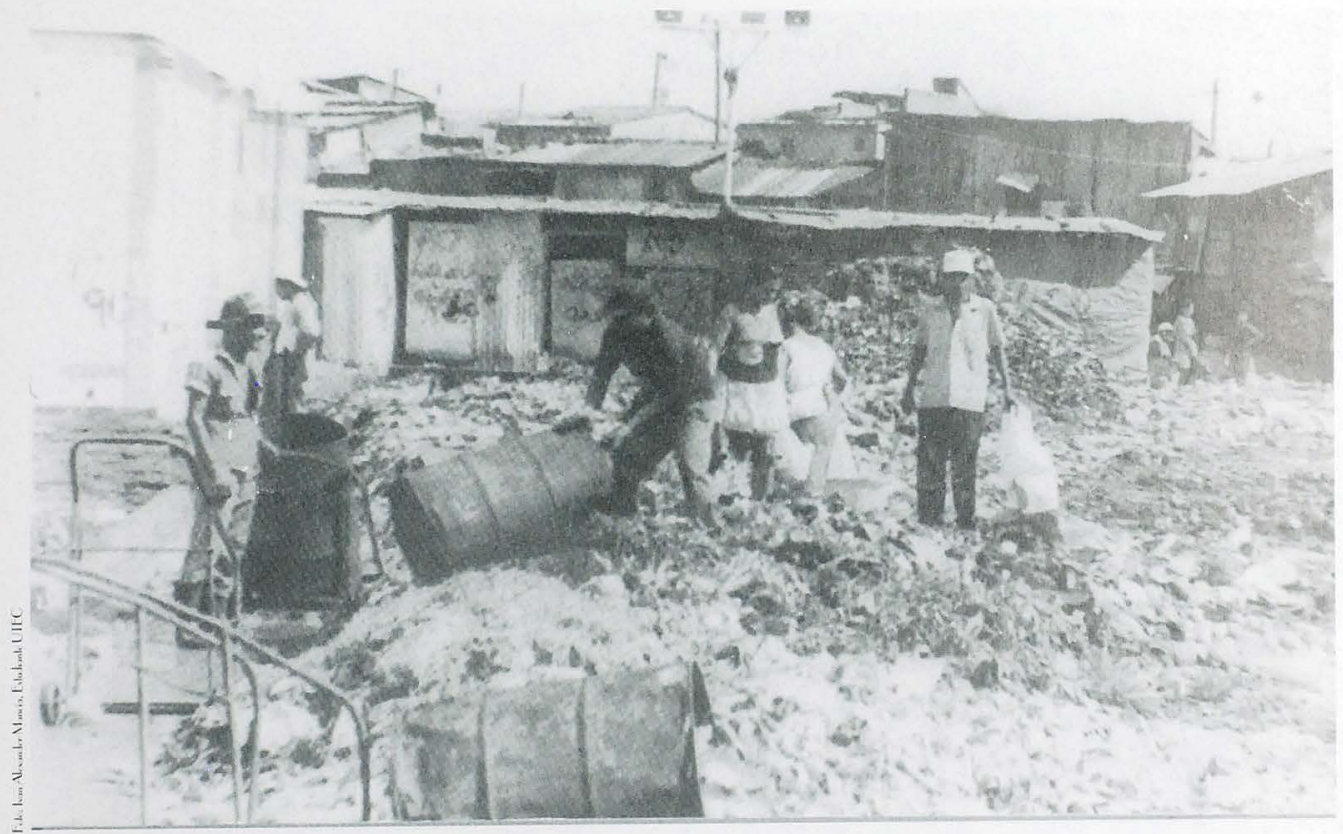




\section{Circunstancias Económicas}

internacionales es cuestión de imagen financiera interna y externa. Ademas del interés de las autoridades económicas por preservar una política de cambio fijo, dentro de un contexto de política financiera, en la cual adquiere relevancia un manejo de los instrumentos monetarios adecuado para contrarrestar la amenaza persistente de un mayor déficit fiscal. Tales instrumentos no son otros que la tasa de interés, el encaje legal y las operaciones de mercado abierto. Sin embargo, esa polírica monetaria restrictiva ha tenido su costo de sacrificio, crecimiento productivo y niveles de empleo, difícil de cuantificar; pero si fundamentada en la experiencia nacional e internacional. Cabe mencionar que las entradas en concep to de remesas de trabajadores han perdido en el pasado reciente su dinamismo, ya que en 1999 sólo crecieron en un $2.6 \%$, pero que si se toma en cuenta su comportamiento y acumulación en los años noventa ha sido el soporte de la política económica, la base del dinamismo de la intermediación financiera $y$ hasta de cambio en los patrones de conducta y de consumo de muchos salvadoreños.

La política de tipo de cambio fijo ha sido estimulada por la aparente atracción inicial de dos gobiernos consecutivos de dolarizar la economía, basado en la importante cuantía que se tiene en dólares con relación a la base monetaria, circunstancia que cuantitativamente posibilita, a juicio de expertos monetaristas, la conversión de la moneda local de curso legal a la moneda en referencia; menospreciando la fuente circunstancial de las divisas y resaltando las supuestas bondades en términos de preservación del ingreso y capacidad de compra real del dólar y de la mayor posibilidad de mantener tasas de interés bajas, como las prevalecientes en los Estados Unidos. Con ello estimular la inversión local y extranjera, sin dejar de reconocer que una decisión de esa índole no sería la panacea para resolver los males del subdesarrollo y que los inversionistas ponderan significativamente el entorno sociopolítico, en el cual prevalecen las condiciones de seguridad ciudadana que ofrece un espacio geográfico específico.

La cuenta de capital y financiera ha mostrado saldos superavitarios importantes. Las mayores entradas (créditos), correspondieron a inversión extranjera, bonos y pagarés, préstamos y créditos comerciales del exterior; específicamente es importante señalar que recientemente la inversión directa se ha reducido en forma significativa en comparación con períodos anteriores, mientras que los préstamos externos han tendido hacia el alza. El resultado positivo de la cuenta de capital y financiera en
1999, hizo posible contrarrestar el saldo deficitario de la cuenta corriente, lo cual a su vez permitió una acumulación en las reservas internacionales netas, las cuales alcanzaron un nivel récord cercano a los dos mil millones de dólares, equivalente a seis meses de importaciones a nivel FOB.

El desequilibrio del sector externo el año pasado y particularmente de la cuenta corriente de la balanza de pagos, contrarresta los objetivos de estabilización y dinamización de la economía. Al mismo tiempo representa una falta de dinamismo en el supuesto motor del crecimiento de la actividad económica, tal como lo testimonian las cifras sobre intercambio comercial de productos y los ingresos por transferencias (remesas). Un aspecto importante en los ingresos extraordinarios de divisas además de las remesas familiares ya mencionadas, lo constituye la venta de compañías distribuidoras de energía eléctrica y de telecomunicaciones, ingresos que por su naturaleza se dan una sola vez, lo que significa una correlación estrecha entre este tipo de ingresos y el mayor nivel de reservas internacionales. También hace más obvia la necesidad de redoblar esfuerzos para normalizar la dependencia, en el futuro, de ingresos naturales y ordinarios (exportación de bienes y servicios). En este contexto, se considera que la mayor competitividad natural y adquirida (devaluaciones) que presentan otros países, así como el deterioro económico que afrontan los de la región Centroamericana, son grandes retos para el país.

\section{Finanzas públicas}

El déficit fiscal es el talón de Aquiles de una política económica de estabilización en la cual el gobierno ha estado empeñado desde principios de la década de los noventa. En efecto, el Sector Público No Financiero (SPNF), cerró el año con un déficit (incluyendo donaciones) equivalente al $3 \%$ del PIB, el porcentaje más alto alcanzado por el déficit fiscal desde 1992. El resto del gobierno general ha pasado de una situación de superávit a una de déficit; por otra parte, los niveles de ahorro corriente del SPNF y del gobierno central consolidado experimentaron una drástica reducción, lo que podría significar un obstáculo para incrementar la tasa de crecimiento de la economía en el mediano plazo.

Lo más preocupante en la conformación de los ingresos y gastos del gobierno es la poca flexibilidad que existe para un cambio en la estructura, en la ecuación (Ingresos = Gastos). Por una parte, los ingresos tributarios tienen una alta dependencia de tres rubros, en orden de importancia: Impuesto al Valor Agregado,
El déficit fiscal Es el talón de AQuiles di UNA POLÍTICA

ECONÓMICA dE

ESTAbilizaCión EN LA

CUAL El GObIERNO HA

ESTAdO EMPEÑAdO

desde principios de

la década de los

NOVENTA. EN ElECTO,

Sector Público No

Financiero, cerró El

año CON UN déficit

(incluYENdO

dONACIONES)

EQUivaleNTE al 3\% de PIB, el porcentaje más alto alcanzado POR El déficit fiscal desde 1992 


\section{INFORME DE LA UTEC 1999}

LO QUE ES AbsolutAMENIE NECESARIO PARA la CONSERVACIÓN dE UNA ESTABilidad MACROECONÓMICA Y PARA PRESERVAR El INGRESO real futuro de los habitaNIES ES UNA REducCión EfECTIVA dEl déficit fisCal, Ya QUE El CONSERVAR la TENdENCIA CRECIENTE QUE ESTE HA MANifESTAdO, NOS pOdRÍa Ilevar a QUE ESTE ALCANCE NIVElES MAYORES dE UN $5 \%$ CON RElACión Al PIB
Impuesto sobre la Renta e Impuesto de Importación. Por el lado del gasto, el $77 \%$ corresponde a gastos corrientes y de estos el $52 \%$ lo constituyen las remuneraciones, las cuales han experimentado incrementos; no obstante, la política salarial de congelar plazas en el sector público y mantener los niveles salariales. En contraste, los gastos de capital que han sufrido una reducción sistemática son estratégicos desde el punto de vista de las necesidades sociales y como complemento a la inversión privada.

Lo que es absolutamente necesario para la conservación de una estabilidad macroeconómica y para preservar el ingreso real futuro de los habitantes es una reducción efectiva del déficit fiscal, ya que el conservar la tendencia creciente que este ha manifestado, nos podría llevar a que éste alcance niveles mayores de un $5 \%$ con relación al PIB. Una alternativa simplista y comprometedora para las generaciones futuras sería la contratación de mayor deuda interna y externa, como ha acontecido en el año recién pasado, con el agravante que el Presupuesto General de la Nación para el presente año contempla desembolsos adicionales de préstamos externos en cantidades significativas.

Si el ajuste se efectúa por el lado del ingreso se tendrá que recurrir a un incremento en la carga tributaria. Por ejemplo, en el presente año se estima una carga del $12 \%$ del PIB, lo cual representaría un aumento de 1.5 puntos porcentuales del PIB, con respecto a la carga estimada al cierre del ejercicio del año anterior. Si el alcance de ese esfuerzo resultara menor o si el crecimiento del PIB también resulta inferior, la brecha fiscal podría continuar ampliándose, forzando a las autoridades correspondientes a recurrir a desembolsos mayores de préstamo o nuevamente a lo que ha sido la práctica reciente de reducciones en la inversión pública, con las consecuencias negativas ya conocidas.

Si por el contrario, el gobierno pretende hacer un esfuerzo para mantener el nivel de inversión pública, la meta tendrá que ser muy ambiciosa y acorde a los requerimientos de inversión que El Salvador necesita para superar las deficiencias que adolece en diversas áreas productivas y de carácter social, que le permita insertarse competitivamente en los mercados internacionales; alcanzar y preservar una estabilidad social; ésta última, como condición necesaria para asegurar un fortalecimiento productivo y una estabilidad en la moneda.

Las perspectivas del gasto público se tornan más dramáticas cuando se toma en cuenta la carga fiscal que se derivará del financiamiento del régimen público de pensiones. A propósito, existe un agotamiento de las reservas técnicas del Instituto Salvadoreño del Seguro Social (ISSS) y del Instituto de Pensiones de los Empleados Públicos (INPEP). El Ministerio de Hacienda ha estimado que dicha carga ejercerá una importante presión sobre las finanzas públicas.

Todo parece indicar que las alternativas de generar solvencia presupuestaria son escasamente tres: una elevación gradual de la carga tributaria, una optimización en la recaudación impositiva y una reducción del gasto corriente. Desafortunadamente la que debiese ser más factible, es la que en la práctica ha resultado la más inviable por ser la que directa y en forma inmediata afecta los intereses de algunas personas. Posiblemente una captación efectiva de $100 \%$ sería suficiente para cubrir buena parte, sino toda la brecha fiscal, pero el enunciado político no ha pasado de ser eso, una declaración de voluntad política y de buenas intenciones, pero con nulas realidades.

En lo que concierne a los impuestos el margen de maniobra es poco, por cuanto las tasas aplicables son altas, aún cuando revisiones a las legislaciones correspondientes facilitaran cierto grado de aumento en la recaudación. Sin embargo, estas revisiones pueden resultar insuficientes. Se hace necesario dirigir esfuerzos de toda índole, para reducir el déficit fiscal; agotar las posibilidades para mejorar la situación fiscal; incrementar los ingresos del sector público, mediante medidas tendientes a ampliar la base tributaria con impuestos que no afecten a las personas con menor capacidad de pago. O sea, a los sectores de carácter progresivo que evitan la regresividad que son los que caracterizan al sistema vigente.

El gasto corriente ofrece un potencial, si se decide optimizarlo en términos de congelación y supresión de plazas, y hasta de fusión de entes del gobierno con una óprica o visión de racionalidad, sin ninguna connotación y sin compromiso político. De otra forma se tendrá que afrontar un déficit fiscal, que entre más pequeño sea más beneficioso sería para inducir un nivel más elevado de actividad económica, en la medida en que pudiera contribuir a reducir las tasas de interés y propiciar de ésta manera un mayor gasto de inversión privada. Independiente de su cuantía el déficit fiscal como un hecho consumado tendrá que financiarse con compras voluntarias de deuda pública por parte del sector privado en el mercado doméstico, colocación forzosa de deuda pública, financiamiento externo, y transferencia de recursos del banco central. Como afirma FUSADES en una de sus documentos recientes: "En todo caso, cualquiera que sea el mecanismo concreto para financiarlo, la existencia de un déficit fiscal constituye 
por lo general un foco actual o potencial de desequilibrios macroeconómicos que conviene eliminar de raíz. Esta recomendación tiene validez independientemente del régimen cambiario que prevalezca".

La opción que ha venido siendo la práctica para aminorar la mayor cuantía del déficit ha sido la reducción de la inversión publica, como una salida cómoda que no afecta de inmediato a grupos en particular, pero sí a las grandes mayorías que tienen que prescindir de servicios colectivos que sólo el gobierno puede proporcionar. Seguir con esa tendencia sería atentar con la calificación del recurso productivo más valioso y abundante que es la gente y con los mínimos de infraestructura que el país necesita para generar un crecimien to económico sostenible.

Otra tendencia que debiera de evitarse es el recurrir al endeudamiento externo, opción que es frecuentemente utilizada en situaciones de escasa liquidez, sobre todo cuando se presentan oportunidades de obtener recursos en términos relativamente blandos, pero que comprometen los ingresos de divisas futuros, restando de esa manera la potencialidad de un crecimiento sostenido en el mediano plazo.

\section{Sector Financiero}

Después de la reprivatización de la banca como parte de un programa de liberalización financiera, que coincidió con un período de auge económico y de estabilización financiera, en gran parte como consecuencia de los Acuerdos de Paz, la demanda agregada interna (consumo e inversión), experimentó una alza, coyuntural que fue aprovechada por el sector financiero, en particular la banca, ya que la expansión económica en referencia propició y facilitó el endeudamiento, el cual en un principio era, momentáneamente destinado a usuarios, en su mayoría con capacidad de pago, o deudores que en promedios presentaban un menor riesgo crediticio.

En la primera mitad de los noventa el crecimiento económico osciló entre $5 \%$ y $6 \%$. No obstante, a partir de 1996 ese dinamismo perdió fuerza y el sector financiero que es la cara del resto de los sectores productivos no fue la excepción; su contracción, sin duda, constituyen replicas de los crecimientos reales de la economía de mercado que recientemente han manifestado una volatilidad.
Desaceleración que ha dificultado la puntualidad en el plazo de muchos créditos otorgados en periodos de bonanza y de mejores perspectivas.

Las remesas familiares, como se ha reiterado en estas notas y más recientemente la venta de activos, han constituido una fuente significativa y estratégica de divisas cuya monetarización se ha hecho evidente y ha ejercido una presión sobre la política moneraria para que ésta tenga que ser, con sus instrumentos clásicos, de carácter contractivo. Práctica que ha posibilitado una estabilidad de la moneda, pero que también ha tendido sus efectos relativos en el menor crecimiento real de la economía. En efecro, dada la tendencia expansiva de los

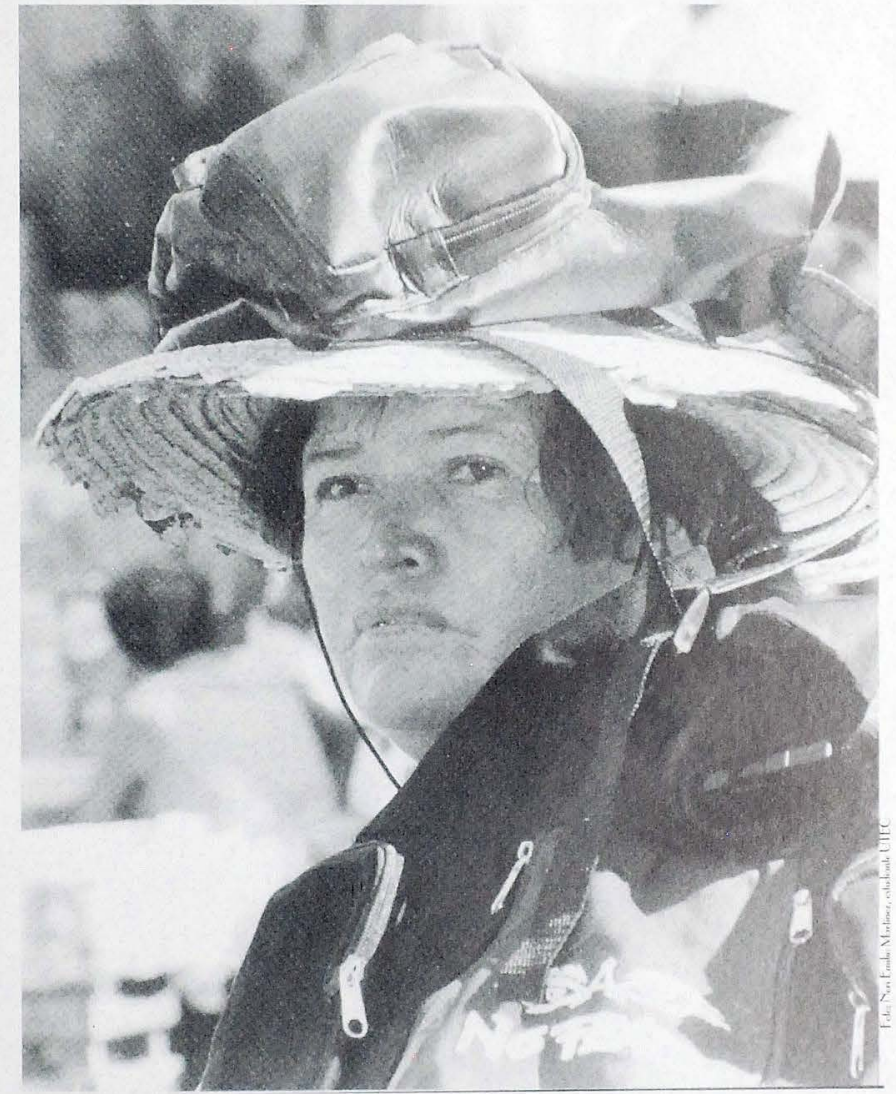

entorno 11 
saldos acumulados de divisas se hizo necesario una mayor regulación de los intermediarios financieros, considerando el empeño de las autoridades monetarias de preservar los niveles de liquidez, en armonía con las metas de inflación y de mantención de un ripo de cambio fijo, opción que ejerció efectos contractivos en la corriente real de la economía.

Se incrementaron los activos externos netos (RIN) pero a cambio de aumentar los pasivos en moneda interna de corto plazo, se aprecia en los saldos de los títulos valores emitidos por el BCR y ha significado un embargo, ese nivel de reservas internacionales, básicamente ha posibilitado una comodidad o un respaldo para una política monetaria de estabilidad de la moneda, no asi, de facilitador del crecimiento y mucho menos de estabilizador social.

Según lo manifestado por las autoridades monetarias y algunas instituciones dedicadas al análisis económico, existe una política monetaria que ha facilitado la estabilidad de precios, tasa de intereses reales positivas con rendimientos superiores a los mercados internacionales y ha procurado mantener la solvencia

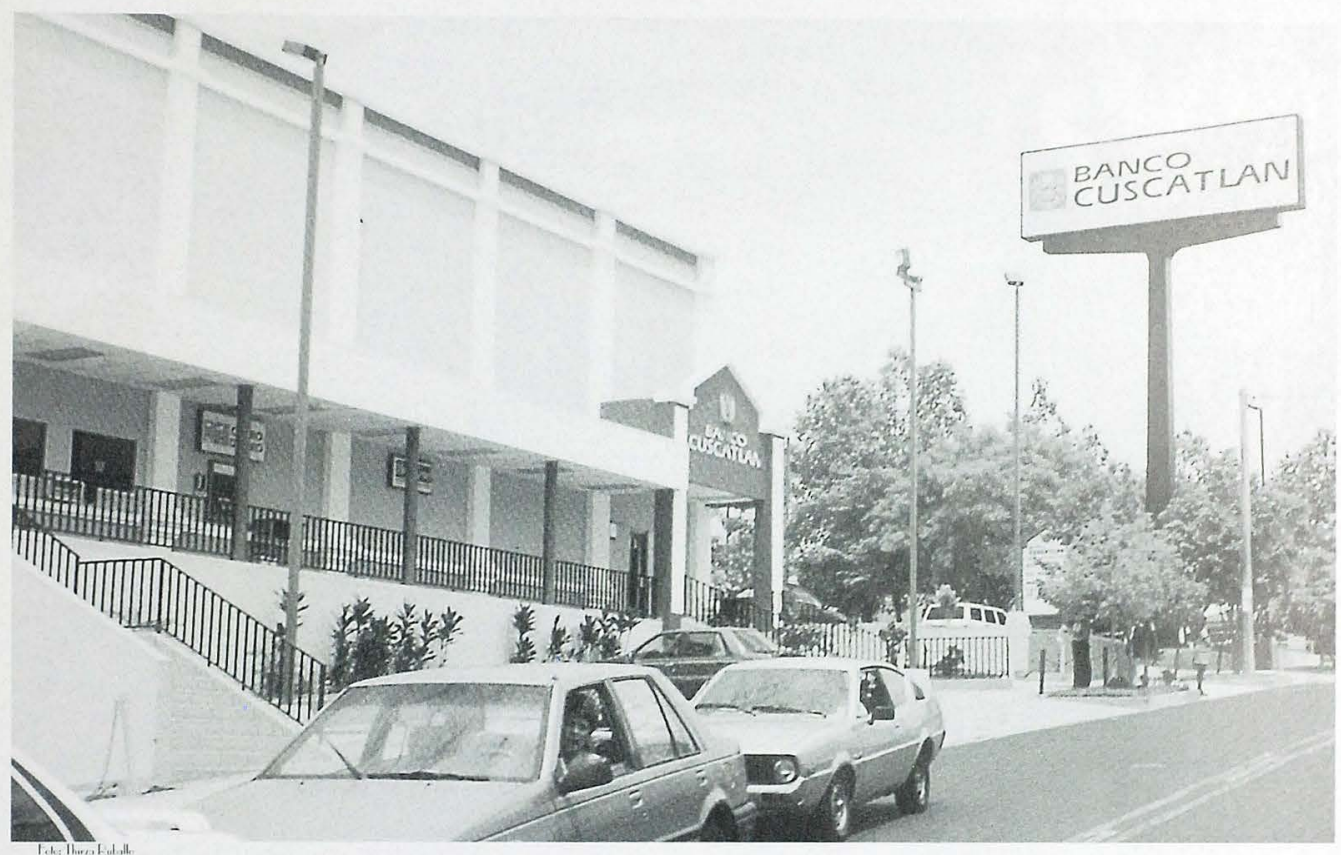

costo derivado de la diferencia de los rendimientos de ambos instrumentos financieros; se argumenta que el beneficio de esta modalidad "es que también logra el beneficio de mantener la estabilidad de precios y no perder RIN con este ejercicio de política monetaria"1 Entre 1991 y 1999 se registró un incremento de mil cuatrocientos cuarenta y cuatro millones de dolares. Incremento que puede calificarse de extraordinario. Sin del sistema financiero; ademas de facilitar el aumento de las tasas de ahorro en el país, bajo el supuesto de que ha existido una confianza en la solidez de las instituciones financieras. Este argumento en alguna forma hace abstracción de las pocas alternativas de inversión que se presentan en períodos de desestabilización o estancamiento económico, así como las bajas tasas de interés prevalecientes en los mercados financieros foráneos, 
principalmente en el área en la cual predomina el dólar. La tasa de ahorro financiero respecto del PIB se expandió en forma sustancial al grado de llegar a un $45 \%$ en 1999 , ahorro que se cuantifica sumando las cuentas de depósitos de moneda nacional y extranjera y títulos valores de la institución financiera.

En la década de los noventa se ha evidenciado una profundización monetaria; sin embargo, los saldos de dinero más líquido que incluye los depósitos a la vista y, billetes y monedas en circulación han venido presentan una tendencia de pérdida de importancia relativa, respecto del PIB al surgir sustitutos del dinero como lo son las tarjetas de crédito, cuentas de ahorro y a plazo con propósitos de inversión.

Las tasas reales positivas desde finales de 1993 por reducciones en la tasa de inflación, registran un subperíodo de tasas reales negativas en el segundo semestre de 1992 y primer semestre de 1993 que coinciden con la vigencia de un incremento en el IVA del 10 al $13 \%$, incremento que ocasionó un ajuste de precios sistemático y generalizado. Esta correlación es lo que nos ha llevado a la afirmación expuesta anteriormente, de que una imposición del IVA a productos sensibles al consumo generalizado y que a su vez tienen una alta ponderación en la canasta básica, pueden volver a generar repuntes en la tasa de inflación.

A pesar de que ha habido una tendencia a la baja en las tasas de interés, los agentes privados han manifestado una constante inconformidad con el nivel de las mismas, lo que ha conducido a una dolarización de los pasivos con la banca comercial, lo cual ha sido considerado razonable dentro de una perspectiva de mediano plazo de tipo de cambio estable. El margen de la tasa de interés activas y pasivas en el mercado financiero interno se ha mantenido relativamente estable entre cuatro y cinco puntos porcentuales. Las operaciones en divisas han experimentado una reducción en las tasas nominales de alrededor de dos puntos, comparando los niveles de 1996 con respecto a los de 1999 para ambos tipos de operaciones activas y de depósito, con lo que el costo del dinero en divisas en el mercado local comparado con el de Estados Unidos refleja una tendencia de reducción en los diferenciales entre ambos mercados, lo que se ha considerado por las autoridades monetarias como un testimonio de "mayor credibilidad en la política de estabilidad cambiaria y la oportunidad de arbitrajes se ha cerrado como normalmente ocurre en las operaciones de este tipo"2
La reprivatización en primer orden, la expansión de una demanda que había estado reprimida a causa del conflicto interno y las causas subjetivas de la demanda identificadas con expectativas favorables a mediano plazo, propiciaron prácticas especulativas tanto de demandantes, como de oferentes de crédito, creciendo la inversión en infraestructura habitacional y comercial. Proyectos, la mayoría sin o con ligeros estudios de mercado, con la premisa que la oferta crea su propia demanda, fueron comunes, y la incorporación de nuevos intermediarios financieros aparecieron en el mercado de dinero. La rentabilidad a nivel unidad empresarial financiera y en promedio fue más que aceptable, debido, en gran parte, a márgenes de intermediación aceptables, mayores volúmenes de negocios, incremento en los saldos de crédito, una mayor redituabilidad y porcentajes de mora prácticamente insignificantes (menores de 4\%).

Como se ha afirmado anteriormente la penetración financiera a lo largo de los noventa ha venido creciendo y el índice de profundización financiera de El Salvador, tal como lo confirma FUSADES en su último informe trimestral de coyuntura, en el cual se asevera que en el segundo quinquenio de los noventa se ha experimentado una concentración en la industria bancaria, la cual es preferible si depara en instituciones más sólidas.

A pesar de esa penetración, profundización y concentración de que se habla el sistema bancario ha empezado ha debilitarse, como consecuencia de una menor acrividad económica y como las piezas de un dominó en caída gradual y paralela, la última en línea se estremece. Bancos con menores rendimientos y las urilidades promedio del sistema reducidas. Una mora arriba del $7 \%$, cuando en el pasado la posibilidad de llegar al $4 \%$ preocupaba a las autoridades supervisoras. Las carteras de crédito son menos recuperables, el riesgo en el otorgamiento del crédito aumenta y las instituciones intermediarias se han vuelto más prudentes en el manejo de sus fondos.

Hay que reconocer que el sistema financiero en su conjunto no experimenta problemas de liquidez; sin embargo, a nivel promedio se experimenta una iliquidez en algunos bancos estatales y en otros de propiedad privada que se han venido debilitando, el sistema financiero no ha podido corregir el problema entre los tiempos en la retención de los recursos captados en concepto de depósitos y el promedio en el plazo de los créditos otorgados, siendo siempre mucho menores los primeros. Por otra parte, el sistema financiero presenta

\section{SE HARÍA NECESARIO}

ESFUERZOS dE TOdA

ÍNdOle PARA REdUCIR

el déficit fiscal,

agotando las

pOsibilidades PARA

MEjORAR la SITUACIÓN

fiscal por el lado de

INCREMENTAR los

INGRESOS dEl SECTOR

público, mediante

MEdidAS TENdIENTES A

ampliar la base

tRibUtaRia CON

impuestos QUE NO

afECTEN a LAS

PERSONAS CON MENOR

capacidad de PAGO 


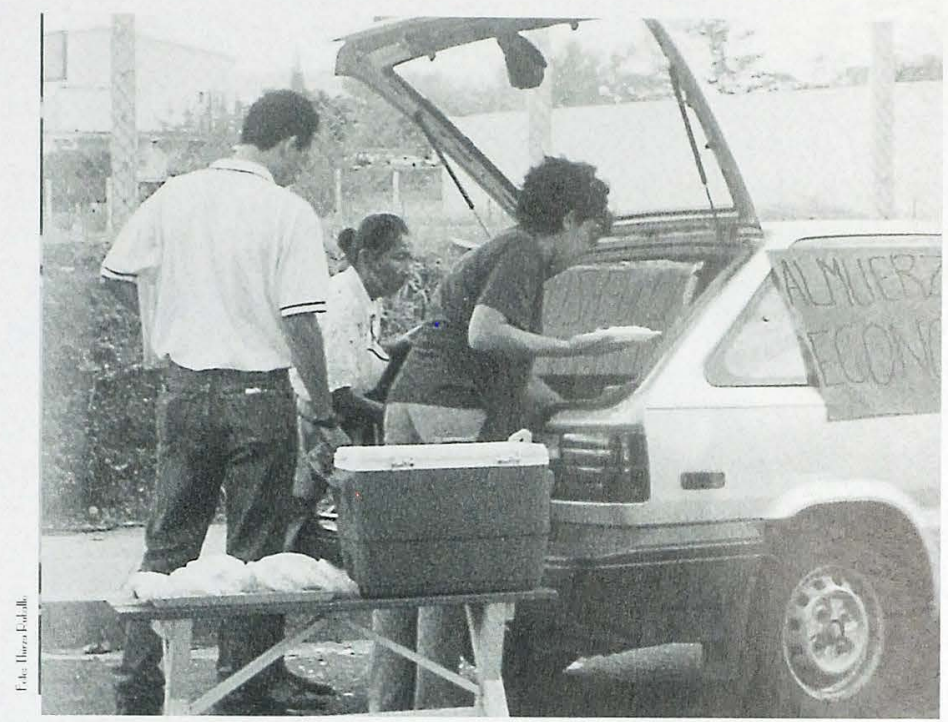

una tendencia de deterioro de la calidad de sus activos, con lo cual el índice de riesgo de los mismos se vuelve superior y la cobertura de provisiones sobre cartera vencida resulta insuficiente.

Se registran seis bancos con índices de vencimiento superiores al $6 \%$, lo cual significa que la mora se encuentra concentrada en esos bancos, el problema se acentúa cuando se observa que los dos bancos que reportan mayor vencimiento de cartera también cuentan con indicadores más bajos de cobertura de reserva y los activos inmovilizados, se han incrementado y su relación con respecto al patrimonio se ha duplicado en los últimos años. Los activos de riesgo se concentran en sectores que producen bienes no transables, lo cual es consecuente con una menor rentabilidad en actividades productivas que en el pasado fueron bastante rentables y que hoy presentan un deterioro en su rendimiento.

De acuerdo a cifras recientes la Industria Bancaria presenta una clara tendencia a la concentración, se ha puesto en evidencia con la tendencia a la fusión. Ello resulta favorable debido a que el resultado final será una mayor solidez del sistema, ya que es preferible tener menos instituciones más sólidas que varias, de las cuales algunas de ellas presentan problemas de solidez y rentabilidad. Esta tendencia se inició después de que en 1996 llegaron a existir 21 instituciones intermediarias, para este año habrá 14 luego que se concentre las fusiones de los Agrícola Comercial y Desarrollo y la del Salvadoreño con BANCASA; tomando en consideración los últimos resultados, el numero de bancos podrían llegar todavía a ser menor.

No obstante lo anterior, el Sistema Financiero en promedio registra un adecuado nivel de solvencia y las instituciones han venido cumpliendo con las disposiciones que establecen las leyes financieras, el indicador que mide la solvencia es el coeficiente resultante de dividir el fondo patrimonial (o patrimonio neto) y la suma de los activos ponderados, el coeficiente debería ser del $10 \%$ como mínimo y la tendencia es de establecer un piso del $12 \%$ en el 2005. De acuerdo a cifras obtenidas la solvencia patrimonial de la Banca esta por arriba del $10 \%$, debido a las medidas de capitalización adoptadas por las empresas intermediarias de fondos liquidos, práctica que deberá ser continuada para mantener los niveles de solvencia requeridos, tomando en consideración que en el entorno económico en que tendrá que desenvolverse el sector financiero es el de una desestabilización con visos de crisis.

La rentabilidad es otra variable que ha venido deteriorándose, altamente influenciada por las pérdidas de los bancos estatales y tres bancos privados, 
Todo parece indicar

QUE El NÚMERO $d E$

bANCOS IENdERÁ A

REdUCIRSE AUN MÁS,

SIENdO RECOMENdAblE

UNA POĹ́tica dE aPERTURA

a bancos EXTRANJEROS, A

fiN dE CREAR UNA

COMPETENCIA SANA QUE lE

PROPORCIONE MAYOR

CREdibilidad al SISTEMA Y

IE CONFIERA beneficios al

USUARIO

Hipotecario, Fomento Agropecuario, Unibanco, Bancasa y Ahorromet. Los tres últimos bancos deberían fusionarse y para los dos primeros debería darse una solución definitiva. Hay que considerar que el tamaño efectivo del mercado financiero se ha reducido sustancialmente en vista de la reducida demanda, los altos índices de mora, la insolvencia crediticia de muchas empresas con categoría de C, D y E en el rango de categorías de riesgo y el menor ritmo de actividad económica que reduce paralelamente el tamaño del mercado de dinero y de capitales a nivel interno. Todo parece indicar que el número de bancos tenderá a reducirse aun más, siendo recomendable una política de apertura a bancos extranjeros, a fin de crear una competencia sana que le proporcione mayor credibilidad al sistema y le confiera beneficios al usuario.

La calidad de los activos en la cual ha influido una política reiterada de refinanciamiento, forzada por los problemas de crecimiento lento de la economía, ha incidido negativamente en los rendimientos de los bancos; sin duda el crédito relacionado que en el pasado se otorgó con bastante frecuencia, significó una concentración del crédito que siempre llevó implícita un mayor riesgo.

Los márgenes de intermediación de la banca han sido un tema muy debatido, son los resultantes entre las tasas activas $y$ las tasas pasivas, se han reducido desde el $2.28 \%$ de 1995 hasta el 0.95 a marzo del 2000. Según el informe, niveles de márgenes inferiores al $1.5 \%$, en la mayoría de los bancos denotan que se tiene escaso margen para absorber una reducción de las tasas de interés, como lo vienen exigiendo los sectores productivos. Estos últimos lo ven desde el punto de vista de las tasas activas. Pero tan importantes son una reducción de éstas, como el hecho de que reducir las tasas de interés pasivas es prácticamente imposible, sin afectar la tasa doméstica de ahorro y la inversión extranjera.

El asunto se agrava, porque la industria bancaria no ha logrado experimentar eficiencia por la vía de los gastos operativos, con respecto a los activos productivos. También los gastos de activo fijo (como edificios, entre otros), habrán de haber incidido en sus costos de operación. Los costos administrativos a corto plazo de los bancos se muestran inflexibles; además los bancos también tienen que tomar muy en cuenta en sus ajustes de tasas de interés el precio internacional del dinero, el cual ha estado aumentando en los Estados Unidos para evitar un recalentamiento de la economía, producto de su actual empuje, que la lleve a una posterior etapa de estancamiento.

Como consideraciones de cierre, es sumamente responsable recomendar una continuada capitalización y una celosa y estricta política de reserva, para el cumplimiento de estos requerimientos. El fortalecimiento y el actuar independiente del ente supervisor es vital, esas medidas son las que permitirán neutralizar las debilidades en la calidad crediticia.

En vista de la vulnerabilidad cada vez más evidente de los bancos y la continuidad de problemas de recuperación crediticia, la fusión parese inevitable y aun cuando podría interpretarse como un promoción oligopólica, la concentración de operaciones le confiere mayor solvencia al sistema y garantiza, lo más importante: los intereses del usuario del sistema.

En vista que reducir las tasas de interes y el vía margen de intermediación, considerado imposible, algo tendrá que hacerse vía costos operativos y administrativos, porque reducciones en las tasas pasivas para continuar satisfaciendo el deseo de menores tasas activas, puede resultar una práctica de subsidio del ahorrante al inversionista de altos costos, en términos de un menor ahorro financiero y una inversión menor a la deseable por ser otros factores, diferentes al costo financiero, los que inciden en la renuncia a invertir.

Finalmente es preciso disponer de una ley de quiebras para disponer de un marco legal y también de un marco institucional con recursos, para prever $y$ solventar eficazmente la salida de bancos u otras operaciones. ¿ 